\title{
Host-parasite interface of fish acanthocephalans. I. Acanthocephalus anguillae (Palaeacanthocephala) in naturally infected fishes: LM and TEM investigations
}

\author{
Horst Taraschewski
}

Institut für Spexielle Zoologie und Parasitologie, Ruhr-Universität-Bochum, D-4630 Bochum, Federal Republic of Germany

\begin{abstract}
Nine species of freshwater fish from Ruhrlake (FRG) were investigated for infection with Acanthocephalus anguillae over 2 yr Prevalence rates of infected fish did not depend on season and were as follows: Leuciscus cephalus (chub) $84 \%$, Tinca tinca (tench) $44 \%$, Abramis brama (bream) $34 \%$, Anguilla anguilla (eel) $30 \%$, Rutilus rutilus (roach) $16 \%$, Alburnus alburnus (bleak) $15 \%$. Mean intensities ranged from 1 to 7 worms per fish. Chub was the major host in terms of both prevalence and intensity of infection. For investigations on the host-parasite interface Salmo trutta (brown trout), $S$. gairdneri (rainbow trout) and Leuciscus leuciscus (dace) from other biotopes were also included. In chub, tench, eel, dace and bleak the worms penetrated the intestinal wall by their presoma up to the muscularis or even perforated it completely. In these hosts, living or dead worms were also found within the peritoneal cavity and/or viscera. In roach and bream the worms did not penetrate the muscularis, whereas in brown and rainbow trout they never penetrated the stratum compactum. The hosts' inflammatory tissue consisted of 3 zones. The first layer, of necrotic cells and degranulated granulocytes, was found adjacent to the surface of the parasite. This necrotic zone gradually passed over to a second layer of mostly intact eosinophilic and heterophilic granulocytes and fibroblasts. The third and outermost layer consisted of collagenous fibers and a few fibroblasts and granulocytes. The fibrous outer layer was only found in those hosts where the worms penetrated the muscularis. A semiliquid, osmiophilic layer between worm-presoma and host tissue was conspicuous in all fish species.
\end{abstract}

\section{INTRODUCTION}

During the last 50 yr numerous papers have dealt with the histopathology of acanthocephalans in fish, most based on paraffin sections of species from naturally infected hosts (Steinsträsser 1936, Wurmbach 1937, Prakash \& Adams 1960, Bullock 1963, Chaicharn \& Bullock 1967, Esch \& Huffines 1973, Schmidt et al. 1974, George \& Nakadal 1981, 1982, McDonough \& Gleason 1981). Recently Wanstall et al. (1986) reported electron microscopical results on Pomphorhynchus laevis in experimentally infected rainbow trout. Investigations on acanthocephalan histopathology in birds (Pflugfelder 1956, Moore \& Bell 1983) and mammals (Chandler 1953, Takos \& Thomas 1958, Richart \& Benirschke 1963, Moore 1979, Tesana et al. 1982, Leng et al. 1983, Nelson \& Nickol 1986) have also been mainly confined to light microscopical studies except for a scanning electron microscopical examination of the rat intestine experimentally infected with Moniliformis moniliformis (Martin et al. 1983).

Little information on the fine structure of acanthocephalan probosces and presomas is available, although the proboscis with its hooks is in most intimate contact with the host's tissue and defense cells. Hammond (1967) described the proboscis tegument of Acanthocephalus ranae and Hutton \& Oetinger (1980) the proboscis hooks of larval Moniliformis moniliformis.

The present article is the first of a series of comparative light microscope (LM), scanning electron microscope (SEM) and transmission electron microscope (TEM) investigations on the host-parasite interface of fish acanthocephalans in naturally and experimentally infected final hosts, and of descriptions of the proboscis 


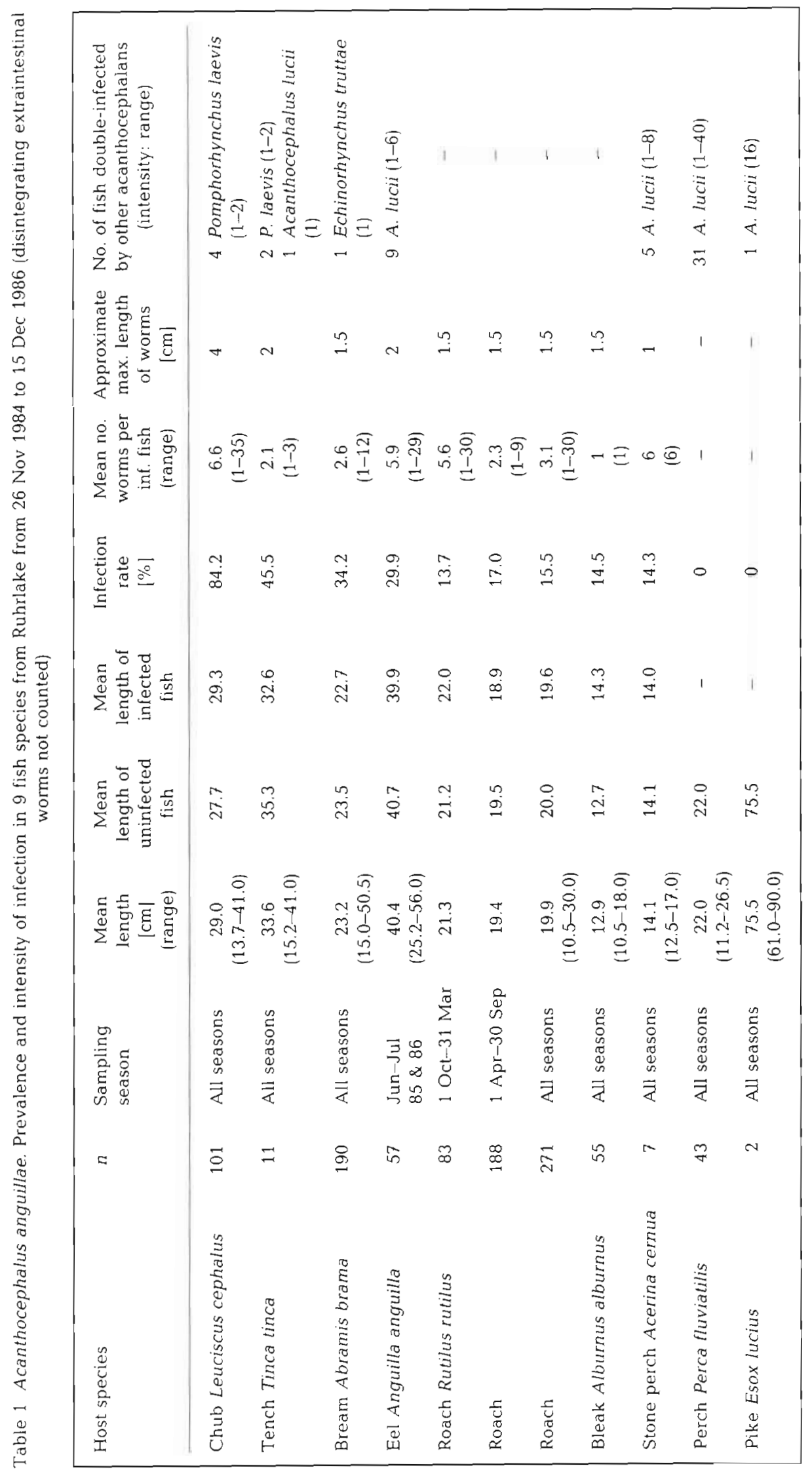


ultrastructure. Acanthocephalus anguillae is the most widespread fish acanthocephalan in Germany (Taraschewski 1985) and is thus considered first. Field data on $A$. anguillae in naturally infected chub are treated here, but detailed results on the host-parasite interface for this species will be published elsewhere (Taraschewski unpubl.).

\section{MATERIALS AND METHODS}

Hosts and parasites. Fish naturally infected with Acanthocephalus anguillae were used exclusively in this study. Nine species of fish (Table 1) were collected in the Federal Republic of Germany from the artificial Ruhrlake (Kemnader See) near Bochum, while from the river Lippe near Hamm, only dace Leuciscus leuciscus were collected; brown trout Salmo trutta and rainbow trout $S$. gairdneri were obtained from the river Leinbach near Heilbronn. Dace and the 2 species of trout did not occur in the Ruhrlake. All fish were transported alive to the laboratory in Bochum, where they were kept for up to $2 \mathrm{~d}$. After killing, the fish were opened immediately. The size of $A$. anguillae individuals contained within the intestine or viscera was estimated by naked eye. For quantitative evaluation of infections, only fishes from the Ruhrlake were used. It was established that $A$. anguillae was the main acanthocephalan species during all seasons and in all 3 biotopes. Intestinal samples with attached worms were taken from the hosts immediately after their death and treated as described below.

Light microscopy. Squash preparations of intestinal samples (of about $3 \mathrm{~cm}$ in length) were photographed between 2 glass plates. Pieces of up to $1 \mathrm{~cm}$ in diameter containing a presoma of Acanthocephalus anguillae were fixed in Bouin's solution, embedded in paraffin, sectioned at 5 to $7 \mu \mathrm{m}$ and stained with Azan-stain or aldehyde-fuchsin stain after Goldner (Burck 1982). The descriptions are based on 5 worms from each host species.

Electron microscopy. The worm's trunk was cut off behind the neck region, and portions of the fish's gut of up to $3 \mathrm{~mm}$ around the worm's point of attachment were fixed in $5 \%$ glutaraldehyde buffered with $0.1 \mathrm{M}$ sodium cacodylate, $\mathrm{pH} 7.4$ at $4{ }^{\circ} \mathrm{C}$ for 24 h. Postfixation was done in $2 \% \mathrm{OsO}_{4}$ in the same buffer. Samples were dehydrated in a graded ethanol series, transferred to propylene oxide and embedded in Araldite. Semithin sections were stained with methylene blue and Azur A. Ultrathin sections were stained with uranyl acetate and lead citrate and examined in a Zeiss EM 9. Measurements of mean values of width and length were calculated from 10 granula of each of 10 granulocytes.

\section{RESULTS}

\section{Field studies}

Prevalences and intensities of infection with Acanthocephalus anguillae in 9 host species from Ruhrlake are given in Table 1. There was neither a seasonal variation in infection (shown only for roach in the table) nor a relation between fish length and infection rate. Among the 9 species of fish only perch and pike were never infected with $A$. anguillae (dace, brown and rainbow trout did not occur in the Ruhrlake). All the other species were infected. Chub was most frequently infected and harboured the highest numbers of worms. In addition, female worms from chub measured up to $4 \mathrm{~cm}$ in length while worms from other hosts were smaller. Perch, stone perch and pike were more frequently infected with Acanthocephalus lucui than with A. anguillae (Table 1).

\section{Host-parasite interface}

In general female worms provoked a more pronounced host reaction than males (Fig. 1). The hosts could be divided into 3 groups based on the depth of the worms' penetration into the intestinal wall.

\section{Group 1}

In eel (Figs. 5 and 6) and in the 3 cyprinids - tench (Figs. 2, 7 and 8), dace (Fig. 11) and bleak - the worms had deeply penetrated the hosts' intestinal wall, either with the presoma alone or together with the anterior metasoma. Worms from these 4 hosts usually broke off at the neck when pulling them out of the intestinal wall. In these hosts whole worms were also found inside the peritoneal cavity (Fig. 2) or inside the viscera. Such extraintestinal worms were either enclosed by a precipitin-like coat (Fig. 2) or by proliferate host tissue. The same applied to chub, but these results will be published elsewhere (Taraschewski unpubl.). All investigated specimens of tench harboured several, mostly dead, worms in extraintestinal locations which, however, were difficult to count, since most of them were already highly disintegrated.

Eel. Most female worms had destroyed the mucosal epithelium, the circular musculature, the overlying longitudinal musculature and the serosa. Compensatory connective tissue had produced a capsule around the worms' presomas. This tissue also extended into the peritoneal cavity, decreasing in thickness with increasing distance towards the side of worms' penetration. The compensatory tissue was either conspicuously 
Figs. 1 \& 2. Acanthocephalus anguillae. Squash preparations in 2 host species (LM). Fig. 1. Rutilus rutilus. Worms with intraintestinal location in roach. Note the hemorrhagic reaction (HT) around the female worms' probosces. Fig. 2. Tinca tinca. Worm with extraintestinal location in tench. Note the precipitin-like cover around the worm (PL) and the proboscis (P) which is not retracted into the trunk
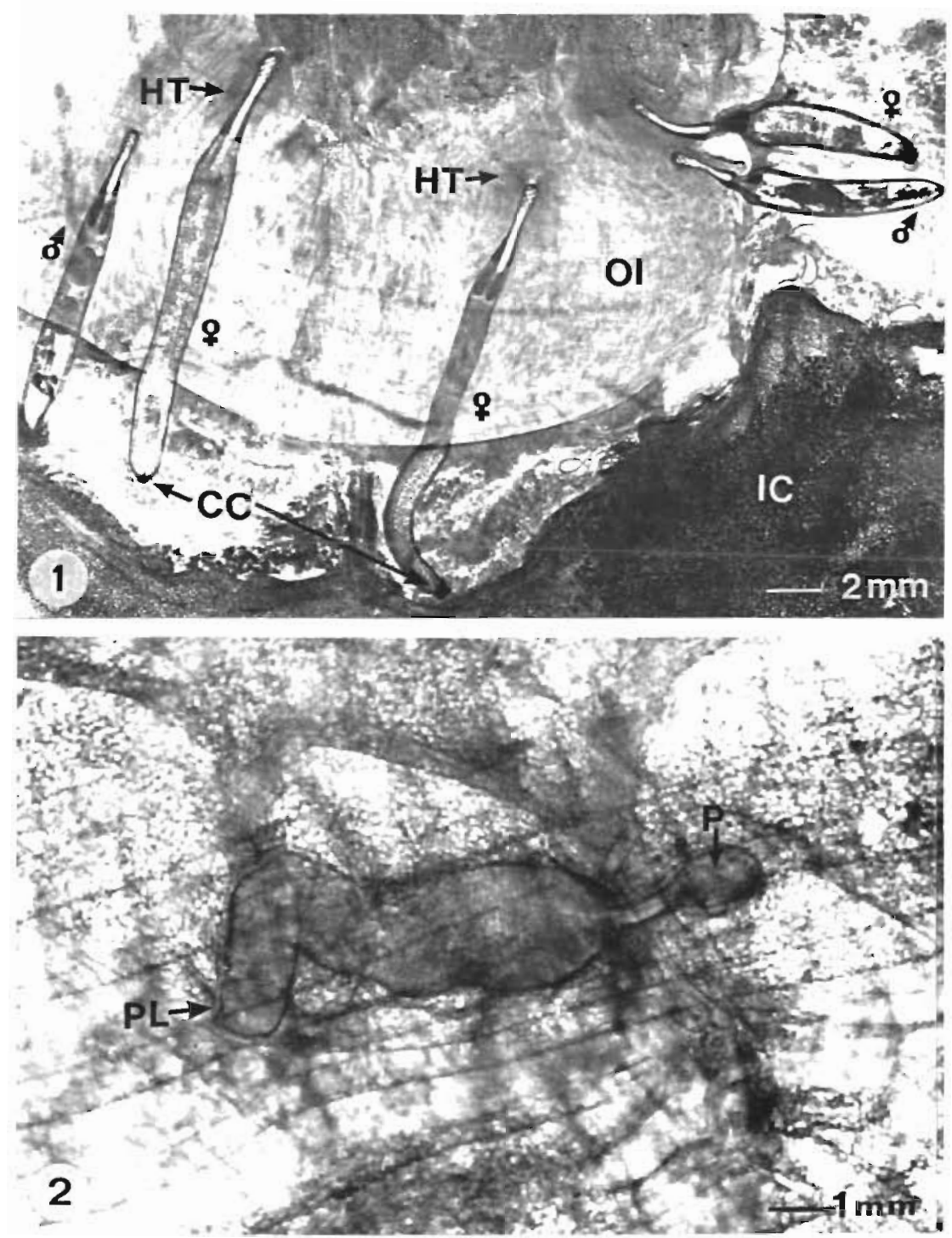

Abbreviations used in figures. Bl: blood; BV: blood vessel (hypertrophic); CB: crystalline bar; CC: copulatory cap; CF: collagenous fibers; CFC: crystalline form of granulum of eosinophilic granulocyte; CG: coarse granula of eosinophilic granulocyte; CGG: coarsely granulated (eosinophilic) granulocyte; DG: discharged granulocytes; RER: rough endoplasmic reticulum; SER: smooth endoplasmic reticulum; EY: erythrocyte; FB: fibroblast; FG: finely granula of heterophilic granulocyte; FGG: finely granulated (heterophilic) granulocyte $\mathrm{H}$ : hook; $\mathrm{HT}$. hemorrhagic tissue; IC: intestinal contents (squeezed out of the intestine); ICM: inner circular musculature; IER: inflated endoplasmic reticulum; IM: inflated mitochondrion; INM: inflated nuclear membranes; IU inclusion of unspecific shape; LE: Iemniscus; LM: longitudinal musculature; LS: lipid-like matter; ME: mucosal epithelium; MI: mitochondrion; N: nucleus; OCM: outer circular musculature; OI: opened intestine; P: proboscis; PA: pancreas; PH: perforated outer layer of hook; PI: proboscis inverted; PL: precipitin-like coat; PLM: pack of longitudinal muscles; PT peritoneal cavity; RL: remnants of granula from heterophilic granulocytes; SC: stratum compactum; SE: serosa; SG: stratum granulosum; SP: space between worm and host due to fixation; TC: tegumental crypt; TP: tunica propria; WT: worm's tegument

solid (staining blue in the Azan-stained sections) and in such cases only slightly hemorrhagic (Fig. 5), or contained numerous hypertrophic blood vessels (Fig. 6), or appeared highly hemorrhagic as shown by an ultrathin section (Fig. 12). The infiltrated erythrocytes showed a shiny orange colour in Azan-stained paraffin sections (Fig. 9). In 2 cases the tunic propria and the circular musculature around the point of attachment were thickened.
Tench. In tench all female worms' presomas had penetrated the outer layer of circular musculature and destroyed the packs of longitudinal musculature in front of them. The inner layer of circular musculature had been ruptured and was mostly found to be pushed ahead and incorporated into the compensatory tissue encircling the worms' presoma (Fig. 7). In transverse sections through the anterior trunk and host's mucosa around the worms point of attachment, a heavy dis- 
charge of coarsely granulated granulocytes from the lesions was observed (Fig. 8).

Dace and bleak. A typical position of a worm in dace is shown in Fig. 11. The worm was still in contact with the intestinal lumen by its posterior trunk while the anterior trunk and the presoma had protruded into the peritoneal cavity. In bleak, both worms and fish showed a similar behaviour as described for dace.

\section{Group 2}

The second group of hosts consisted of the 2 cyprinids bream and roach. In these hosts the probosces of the worms only penetrated up to the tunica propria or up to the inner portion of the circular musculature (Figs. 9, 10). A solid capsule of connective tissue surrounding the probosces was not seen. Among the 190 specimens of bream and the 271 specimens of roach investigated (Table 1) no worms were found in extraintestinal locations. Nevertheless the tissue in proximity to the proboscis was hemorrhagic (Figs. 9, 10 inset), the tunica propria was enlarged (Fig. 10) and granulocytes were discharged from the lesions (Fig. 10). In bream and roach the most pronounced hemorrhagic response was in the tunic propria adjacent to the worm (Fig. 9) in all investigated hosts

\section{Group 3}

The third group of hosts consisted of the salmonids brown and rainbow trout, where all 10 sectioned worm presomas had penetrated only the tunica propria, striking the stratum compactum, a solid layer of collagenous fibers that is lacking in the intestinal wall of the other hosts. The stratum compactum (Figs. 3,4) was shiny green in Golner-stained paraffin sections, blue in Azan-stained paraffin sections and absorbed little colour in the methylene-blue-stained semithin sections. The overlying stratum granulosum (Fig. 3) was rich in coarsely granulated granulocytes, which were also found in this layer in uninfected fish (Fig. 3). In infected fish the stratum compactum was occasionally thickened and/or hemorrhagic (Fig. 4) in proximity to the proboscis. Heavy discharge of granulocytes as illustrated for tench (Fig. 8) was noted in 3 cases.

\section{Electron microscopy}

Generally there were 3 zones of compensatory host tissues around the parasites probosces or presomas. Zones 1 and 2 were rather similar in all hosts, whereas the outer fibrous zone (Zone 3) only occurred in those hosts where the parasites had penetrated the muscularis.

\section{Zone 1 (necrotic zone)}

In close proximity to the worms' probosces or presomas the host tissues were completely necrotic (Figs. $12,13,17$ and 18). The cells and organelles of the degenerating cells showed the typical symptoms of degeneration such as cloudy swelling. The mitochondria were swollen and the endoplasmic reticulum and nuclear membranes suffered from dilation and vesiculation (Fig. 12). Granula of degenerating granulocytes were also constituents of this zone (Figs. 13 and 18). The granula either had the same shape as those inside the finely or coarsely granulated granulocytes or were transformed into crystalline granules with patchy distribution of the electron-dense material (Fig. 18). This zone close to the parasite was also locally interspersed with free erythrocytes (Fig. 12). In a few sections disrupted collagenous fibers were found which obviously derived from Zone 3 and were pulled into Zone 1 by the action of the proboscis hooks (Fig. 17). In all hosts a semiliquid osmiophilic coat between the worms' presomal tegument and hooks and the necrotic host tissue was noted (Figs. 13, 16, 17 and 18). Material of the same lipid-like appearance was also detected inside the worms' outer tegument (i.e. in the striped and vesicular zone; Figs. 13 and 16), outside the hooks (Fig. 17 ) and inside the hooks' outer layer and the underlying osmiophilic layer (which are derivates of the tegument's striped layer and vesicular layer, respectively; Taraschewski 1988) (Fig. 17). Large drops of non-membrane-bound lipid-like substance were included within the necrotic host tissue and eventually incorporated into the coat of the host-parasite interface (Figs. 13 and 16). Large drops and thick coats were usually less osmiophilic than small droplets and thin coats (Figs. 13 and 16).

\section{Zone 2 (granulocyte zone)}

Externally the necrotic zone gradually turned into Zone 2 which was characterized by solid inflammatory tissue. Most of its cells were still intact. Among other cells, in all hosts the major constituents were 1 or 2 different types of granulocytes. In eel only finely granulated granulocytes containing elongated cytoplasmic granula with fine longitudinal striations were found (Figs. 12, 13 and 14). These granula measured about $800 \times 220 \mathrm{~nm}$. Beside these granulocytes collagenic embedded cells with inclusions of unspecific shape also occurred (Fig. 15). A few finely granulated granulocytes harboured similar inclusions (Fig. 14). In tench 
finely and coarsely granulated granulocytes occurred (Figs. 18 to 22). The granula of the finely granulated granulocytes were elongated, contained a central longitudinal crystalline bar and measured about $350 \times$ $100 \mathrm{~nm}$ (Fig. 21). The granula of intact coarsely granulated granulocytes were ovoid and devoid of any structures, measuring about $800 \times 600 \mathrm{~nm}$ (Fig, 22). Blood accumulations found in this zone were often enclosed by blood vessels. The granulocyte zone also contained a few cells tentatively identified as lymphocytes, plasma cells and mononucleate macrophages. It was also interspersed with fibroblasts and strands of collagenic fibers (Figs. 15 and 20).

\section{Zone 3 (fibrous zone)}

In those hosts where the muscularis was penetrated by the worms' presomas the outermost layer of substitutional tissue consisted of broad strands of collagenic fibers, of fibroblasts and of interspersed granulocytes (Fig. 19). In many cases fibrosis was more progressive than shown in Fig. 19. Around the presomas of large worms this zone was very solid especially around the worms' necks.

\section{DISCUSSION}

\section{Field studies}

The field studies (Table 1) showed that chub was the major host of Acanthocephalus anguillae in the Ruhr- lake. The other 6 host species from this biotope (eel, tench, bream, roach, bleak and stone perch) were additional hosts or were major hosts of $A$. Iucii (perch, stone perch, pike). The fish species obtained from other biotopes cannot be compared to species from the Ruhrlake, since they had been exposed to different ecological conditions. Data from the field and from the histological investigations combined may be interpreted as follows.

\section{Age of infection}

The present investigations have shown that a few species of hosts harboured large worms that had deeply penetrated into the intestinal wall. In other hosts the contained worms were comparativeiy smailer and had caused only superficial lesions in the intestinal wall. In chub, which harboured the largest worms, the histopathological changes induced by the parasites were most conspicuous. Nearly all worms, at least all older fernales, had penetrated the entire intestinal wall with their presomas. The host had built up voluminous fibrous capsules around them usually containing granulomas and a broad necrotic zone (Zone 1) along the surface of the worm (Taraschewski unpubl.). Investigations on rainbow trout experimentally infected with Acanthocephalus anguillae have shown that worms of 2 to 6 mo post-infection also reached a size of almost $3 \mathrm{~cm}$. These worms, unlike in the present investigation, had penetrated the stratum compactum and provoked an almost similar host reaction as the large worms in the naturally infected chub. In experimentally infected

Figs. 3 to 11. Light micrographs of histological sections through the intestinal wall of 6 species of fish naturally infected with Acanthocephalus anguillae. Paraffin sections: Fig. 3, Goldner-stained; Figs. 4, 5, 7, 9, 10 inset, 11, Azan-stained. Figs. 6, 8, 10: semithin Araldite sections. Fig. 3. Salmo trutta. Longitudinal section through the intestinal wall of brown trout showing the typical stratification of a salmonid's intestinal wall. Note the conspicuous stratum compactum (SC) that is absent in the other fishes' intestinal wall. Bar $=10 \mathrm{~km}$. Fig. 4. Salmo trutta. Longitudinal section through the inner intestinal wall of a brown trout with attached worm's proboscis. Note that the worm (upper proboscis inverted: PI) fails to penetrate the stratum compactum. A hemorrhagic reaction (HT) is present in the stratum granulosum (SG) at the tip of the proboscis. Bar $=25 \mu \mathrm{m}$. Fig. 5. Anguilla anguilla. Longitudinal section through the intestinal wall of an eel with attached worm's presoma (transverse section of the intestinal tube). Note penetration of the circular (CM) and longitudinal musculature (LM) and the formation of a capsule of connective tissue (CT) around the presoma. Bar $=200 \mu \mathrm{m}$. Fig. 6 . Anguilla anguilla. Longitudinal section through an eel's inflammatory tissue near the worm's anterior proboscis showing a hypertrophic blood vessel (BV). Bar $=20 \mu \mathrm{m}$. Fig. 7. Tinca tinca. Longitudinal section through the outer intestinal wall of a tench and a penetrated worm proboscis. Note that the invading proboscis has ruptured the inner layer of circular musculature (ICM), the outer layer of circular musculature (OCM) and 2 packs of overlying longitudinal muscles (PLM). Bar $=50 \mu \mathrm{m}$. Fig. 8. Tinca tinca. Transverse section through the inner intestinal wall of a tench and the attached worm's anterior metasoma. Note the heavy discharge of granulocytes (DG) from the lesion caused by the worm. Bar $=200 \mu \mathrm{m}$. Fig. 9 . Abramis brama. Longitudinal section through the intestinal wall of a bream and transverse section. through an encapsulated worm's proboscis which is bent at an angle of $90^{\circ}$ between the tunica propria (TP) and the overlying circular musculature. The proboscis is partly inverted. Note the hemorrhagic tissue (HT) near the proboscis. Bar $=100 \mu m$. Fig. 10 . Rutilus rutilus. Longitudinal section through the intestinal wall of a roach with encapsulated worm's presoma (lateral section of proboscis). Note the enlarged tunica propria near the proboscis and the discharge of granulocytes from the inner tunica propria. Bar = $100 \mu \mathrm{m}$. Inset: Micrograph showing hemorrhagic tissue near the worm's proboscis. Bar $=75 \mu \mathrm{m}$. Fig. 11 . Leuciscus leuciscus. Longitudinal section through the intestinal wall of a dace and transverse section through the proboscis of a worm lying inside the peritoneal cavity (PT) with its anterior half. The worm s posterior half did not penetrate through the intestinal wall (seen in serial sections). Note that the connective tissue around the proboscis has partly replaced the outer layer of longitudinal musculature. Bar $=50 \mu \mathrm{m}$ 

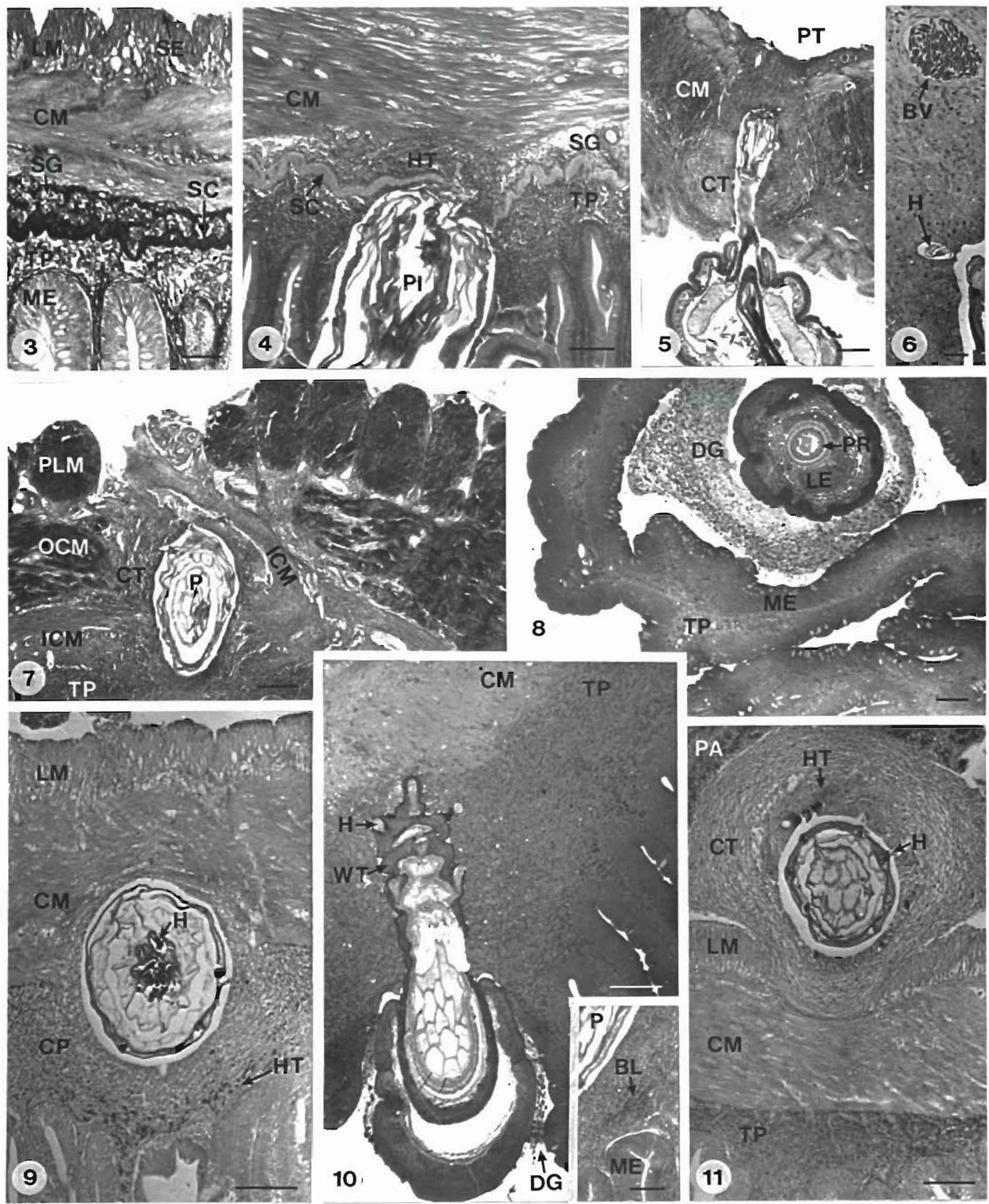

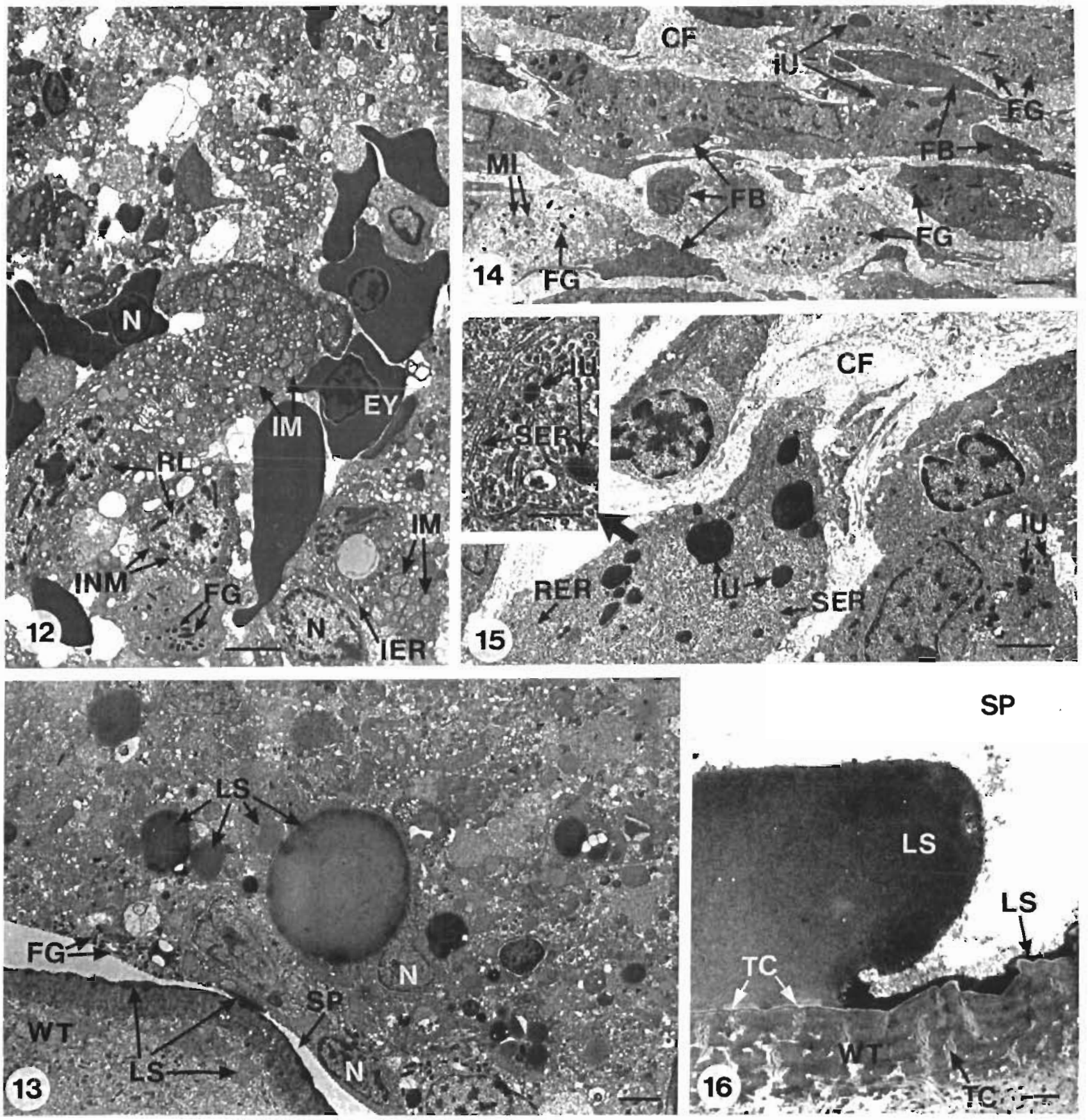

Figs. 12 to 16. Transmission electron micrographs of Acanthocephalus anguillae in eel Anguilla anguilla. Fig. 12. Necrotic zone (Zone 1) near hook with remnants of (probably) leucocytes (RL) and apparently intact erythrocytes (EY). Note the mitochondria (IM), endoplasmatic reticulum (IER) and nuclear membranes (INM) all of which are inflated. Bar = 2 um. Fig. 13. Necrotic zone with remnants of finely granclated (heterophiljc) granulocytes (FG) and other host's cells. Note the lipid-like substance (LS) inside the host tissue, forming a coat between worm and host and inside the worm's tequment (WT). Bar $=2$ um. Firg. 14. Fibrous zone (Zone 3). Note the differently sectioned fibroblasts (FB), the collagenous fibers (CF), the finely granulated (heterophilic) granulocytes (FG) and cells with inclusions of unspecific shape (IU). Bar $=5 \mu \mathrm{m}$. Fig. 15. Granulocyte zone (Zone 2), showing unidentified cells which contained inclusions of unspecific shape and a well-developed ER. Bar = $1 \mu \mathrm{m}$. Insel: Magnified cytoplasma of such a cell. Bar $=0.2 \mathrm{um}$. Fig. 16. Lipid-like (LS) coat covering the surface of the worm's proboscis. Note its different thickness and osmiophilic property and its continuity with the contents of the tegumental crypts (TC). Bar $=1 \mu \mathrm{m}$ 

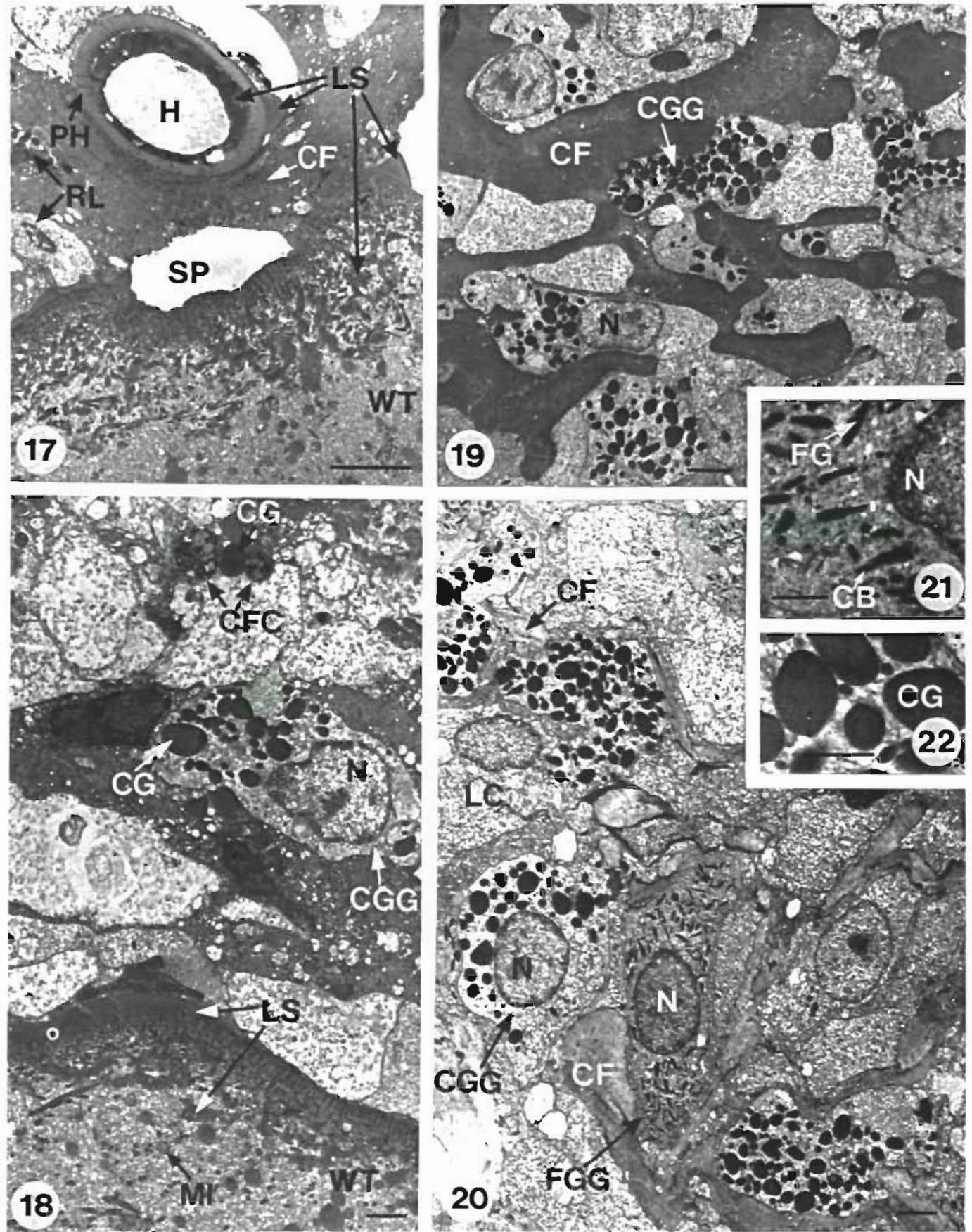

Figs. 17 to 22. Transmission electron micrographs of Acanthocephalus anguillae in tench Tinca tinca. Flg. 17. Necrotıc zone (Zone 1) showing remnants of leucocytes (RL) and collagenous fibers (CF) torn into this zone by a hook (H). Note the lipid-like matter (IS) inside the hook, outside the hook, between worm and host and inside the worm s tegument, also the perforations of the outer hook (PH) that seem to contain the same substance. Bar $=5 \mu \mathrm{m}$ Fig 18. Necrotic zone Note the lipid-like substance (LS) between host and worm tegument and inside the outer tegument (WT). Beside an apparently intact coarsely granulated (eosinophilic) granulocyte (CGG), coarse granula discharged from ruptured eosinophlic granulocytes are also seen. A granulum in its normal form (CG) is accompanied by 2 granula that have turned into a crystallıne form (CFG) Bar $=05 \mu \mathrm{m}$ Fig. 19 Fibrous zone (Zone 3 ) showing collagenous fibers (CF) interspersed with coarsely granulated (eosinophulic) granulocytes and other (unidentitied) cells Bar $=1 \mu \mathrm{m}$. Fig. 20. Granulocyte zone (Zone 2). Note a coarsely granulated (eosmophilic) granulocyte beside a finely granulated (heterophilic) granulocyte (FGG) and narrow strands of collagenous fibers (CF). Bar = $1 \mu \mathrm{m}$. Fig 21. High magnificatıon of a finely granulated (heterophilic) granulocyte Note the central bar (CB) inside the granula (FG). Bar $=0.4 \mu \mathrm{m}$. Fig. 22. Coarsely granulated (eosinophilic) granulocyte; same magnification as Fig 21 Note the homogeneous structure of the granula (CG). Bar 
rainbow trout worms younger than 2 mo were always found held back by the stratum compactum as described here for naturally infected trout species (Taraschewski unpubl.). Thus it can be concluded that the host-parasite interface largely depends on the longevity of a worm in a particular host. Since female acanthocephalans usually live longer and grow larger than males (Nickol 1985), this also could explain the more pronounced host reaction around the probosces of females than of males (Fig. 1). However, other factors such as a different architecture of the intestinal wall (compare Figs. 3 to 11 ) also seem to be important. It is likely that the worms found in bream and roach that had a length of only $1.5 \mathrm{~cm}$ were considerably younger than those found in rhub. tench and eel containing conspicuously larger worms. Consequently the different degree of worm penetration and host reaction is related to the different age of the worms and finally to a different longevity of $A$. anguillae in the investigated hosts. Whether a different longevity of $A$. anguillae in the different hosts is related to the activities of the described types of leucocytes is not clear.

The finely granulated granulocytes of eel have previously been described by Johansson et al. (1974), Kreutzmann (1976) and Klinger (1983). They were identified as heterophilic (neutrophilic) granulocytes. The measurements given for their granula by Kreutzmann (1976) are similar to those presented here. According to Klinger (1983) eosinophilj.c and basophilic granulocytes (as well as monocytes/macrophages) are rare in the blood of eel. Thus, the occurrence of only one type of granulocyte, i.e. heterophilic, in the granulocyte zone around the presoma of Acanthocephalus anguillae fits well with the observations of the other workers. For tench the 2 different granulocytes found here were identified by Bielek (1980). According to her the granulocytes containing the fine elongated granula with the longitudinal bar are heterophils while the granulocytes with the large ovoid granula without a bar are eosinophils. The rarely occurring basophils, also described by Bielek (1980), were not found in this investigation. The cells with inclusions of unspecific shape (Fig. 15) cannot be unequivocally identified.

\section{Size of infected fish and structure of the intestinal wall}

Fingerlings of goldfish and carp experimentally infected with Acanthocephalus anguillae showed worms that penetrated the intestinal wall with their whole body or with their anterior halves (Taraschewski 1985). The same phenomenon is reported here from naturally infected dace and bleak, i.e. small fishes. Thus it is likely that these fishes were too small for an intraintestinal development of $A$. anguillae. Consequently the worms may have tried to invade the nutrient-rich peritoneal cavity or liver and use the fish as a paratenic host. Such behaviour has been reported several times for other fish acanthocephalans (Schmidt 1985). Extraintestinal specimens of A. anguillae in adult chub, tench or eel seem to have invaded the peritoneal cavity accidentally. They were never found in hosts with a shallow worm-attachment. Probably the worms cannot penetrate through the intestinal wall in these hosts. Thus, whether a worm penetrates the intestinal wall or not apparently also depends on the thickness of the intestinal wall (small fishes versus large ones) and on its structure (e.g. stratum copactum present or not).

\section{Zonation of inflammatory tissue}

The worms in natural infections apparently had differing ages; thus acute as well as chronic infections have to be compared. Heavy fibrosis (Zone 3 ) seems to be limited to chronic (i.e. long-term) infections in those hosts which permitted a deeper penetration of the worms. In those hosts with shallow attachment this stage obviously is not reached. Zone 2 was always rich in mostly intact granulocytes in all hosts. Heterophilic as well as eosinophilic granulocytes were found to approach the parasite's surface. They often degranulated in Zone 1 where their granuloma were incorporated into the semiliquid osmiophilic coat. Furthermore, inclusions of the other cells such as the described unidentified cells of Fig. 15 were discharged into this coat. Osmiophilic lipid-like substances were also seen within droplets of the necrotic cells of Zone 1, along the surface of the worms tegument, including the hooks, as well as inside the tegument and hooks. It is not clear whether the host contributes alone to this coat (Fig. 13) or whether parts of the substance are excreted by the worm through its tegumental pores (Fig. 16) and/or through the perforations in j.ts proboscis hooks (Fig. 17). Hammond $(1967,1968)$ described a similar lipid-like coat along the presomal surface of Acanthocephalus ranae from toads and postulated that it had been excreted by the worm. In the present investigation it is shown that the host contributes to the coat (Fig. 13); however, the extent of this has to be measured in further experiments

Acknowledgements. Thanks are due to $\mathrm{Mr} \mathrm{G}$. Künzenbach $\mathrm{Mr} \mathrm{H}$. Ludwig and other members of the Angelsportverein Bochum for providing most of the fishes and to Dr S. Dreyer for making available the trout species from the River Leinbach. I am also grateful to Ms C. Brefeld, Ms G. Strieso and Mr H. Löseke for technical assistance. Prof. Dr H. Mehlhorn generously revised the manuscript. 


\section{LITERATURE CITED}

Bielek, E. (1980). Elektronenmikroskopische Untersuchungen der Blutzellen der Teleostier III. Granulocyten. Zool. Jb. Anat. 103: 105-121

Bullock, W L. (1963). Intestinal histology of some salmonid fishes with particular reference to the histopathology of acanthocephalan infections. J. Morphol. 112: 23-44

Burck, H. C. (1982). Histologische Technik. Georg Thieme Verlag Stuttgart, New York

Chaicharn, A., Bullock, W. L. (1967). The histopathology of acanthocephalan infections in suckers with observations on the intestinal histology of two species of catostomid fishes. Acta Zoologica 98: 1-24

Chandler, A. C. (1953). An outbreak of the Prosthenorchis (Acanthocephala) infection in primates in the Houston Zoological Garden, and a report of the parasite in Nasua narica in Mexico. J. Parasitol. 39: 226

Esch, G. W., Huffines, W. J. (1973). Histopathology associated with endoparasitic helminths in bass. J. Parasitol. 59 (2): 306-313

George, P. V., Nadakal, A. M. (1981). Observations on the intestinal pathology of the marine fish Rachycentron canadus infected with the acanthocephalid worm Serrasentis nadakali. Hydrobiologia 78: 59-62

George, P. V., Nadakal, A. M. (1982). Histopathological changes in the intestine of the fish, Synaptura orientalis (Bl. \& Sch.) parasitized by an acanthocephalid worm, Echinorhynchus veli (George \& Nadakal, 1978). Jap. J. Parasit. 31 99-103

Hammond, R. A. (1967). The fine structure of the trunk and praesoma wall of Acanthocephalus ranae (Schrank, 1788) Lühe, 1911. Parasitology 57: 475-486

Hammond, R. A. (1968). Some observations on the role of the body wall of Acanthocephalus ranae in lipid uptake. J. exp. Biol. 48: 217-225

Hutton, T L., Oetinger, D. F. (1980). Morphogenesis of the proboscis hooks of an archiacanthocephalan, Moniliformis moniliformis (Bremser, 1811) Travassos, 1915. J. Parasitol. 66: $965-972$

Johansson, M. L., Dave, G., Larsson, A., Lewander, K., Lidman, U. (1974). Metabolic and hematological studies on the yellow and silver phases of the European eel Anguilla anguilla. IIl. Hematology. Comp. Biochem. Physiol. 47: 593-599

Klinger, H. (1983). Grundlagen und Anwendung hämatologischer und morphologischer Methoden zur Diagnose von Stress in der Fischhaltung unter besonderer Berücksichtigung des Aals (Anguilla anguilla L.). Diss. Univ. Hamburg

Kreutzmann, H. L. (1976). Untersuchungen zur Morphologie des Blutes vom europäischen Aal (Anguilla anguilla). II Untersuchungen zur Granulopoese. Folia Haematol. 103 $686-700$

Leng, Y J., Huang, W. O., Liang, P. N. (1983). Human infection with Macracanthorhynchus hirudinaceus Travassos, 1916 in Guangdong Province, with notes on its prevalence in China. Ann. Trop. med. Parasitol. 77: 107-109
Martin, J., Crompton, D. W. T., Singhvi, A. (1983). Mucosal lesions in the rat associated with the attachment of Moniliformis (Acanthocephala). J. Helminth. 57: 85-90

McDonough, J. M., Gleason, L. N. (1981). Histopathology in the rainbow darter, Etheostoma caeruleum, resulting from infections with the acanthocephalans, Pomphorhynchus bulbocolli and Acanthocephalus dirus. J. Parasitol. 67 : 403-409

Moore, J. G. (1979). Epizootic of acanthocephaliasis among primates. J. Am. vet.-med. Ass. 157: 699-705

Moore, J., Bell, D. H. (1983). Pathology(?) of Plagiorhynchus cylindraceus in the starling, Sturnus vulgaris. J. Parasitol. 69: $387-390$

Nelson, M. J., Nickol, B. B. (1986). Survival of Macracanthorhynchus ingens in swine and histopathology of infection in swine and racoons. J. Parasitol. 72: 306-314

Nickol, B. B. (1985). Epizootiology. In: Crompton, D. W. T., Nickol, B. B. (eds.) Biology of the Acanthocephala. Cambridge Univ. Press, Cambridge, p. 306-346

Pflugfelder, O. (1956). Abwehrreaktion der Wirtstiere von Polymorphus boschadis Schr (Acanthocephala). Z. ParasitenKde 17: 371-382

Prakash, A., Adams, J. R. (1960). A histopathological study of the intestinal lesions induced by Echinorhynchus lageniformis in the starry flounder. Can. J. Zool. 38: 895-897

Richart, R., Benirschke, K. (1963). Helminths in marmosets. Causes of death in a colony of marmoset monkeys. J. Path Bact. 86: 221-223

Schmidt, G. D. (1985). Development and life cycles. In: Crompton, D. W T., Nickol, B. B. (eds.) Biology of the Acanthocephala. Cambridge Univ. Press, Cambridge, p. 273-305

Schmidt, G. D., Walley, H. D., Wijek, D. S. (1974). Unusual pathology in a fish due to the acanthocephalan Acanthocephalus jacksoni Bullock, 1962. J. Parasitol. 60 $730-731$

Steinsträsser, W. (1936). Acanthocephalen als Forellenparasiten. Z. Fisch. 34: 178-212

Takos, M. J., Thomas, L. J. (1958). The pathology and pathogenesis of fatal infections due to an acanthocephalid parasite of marmoset monkeys. Am. J. Trop. Hyg. 7: 90-94

Taraschewski, H. (1985). Experimental transmission of Acanthocephalus anguillae (Palaeacanthocephala). Z. ParasitenKde 71: 825-828

Taraschewski, H. (1988). Acanthocephala. In: Mehlhorn, H. (ed.) Parasitology in focus. Springer Verlag, New York (in press)

Tesana, S., Mitrchai, J., Chunsuttwat, S. (1982). Acute abdominal pain due to Macracanthorhynchus hirudinaceus infection: a case report. Southeast Asian J. Trop. Med. Pub. Hlth 13: 262-264

Wanstall, S. T., Robotham, P. W., Thomas, J. S. (1986). Pathological changes induced by Pomphorhynchus laevis Muller (Acanthocephala) in the gut of rainbow trout, Salmo gairdneri Richardson. Z. ParasitenKde 72: 105-114

Wurmbach, H. (1937). Zur krankheitserregenden Wirkung der Acanthocephalen. Die Kratzerkrankung der Barben der Mosel. Z. Fisch. 35: 217-231 